Volume 10, No.5, September - October 2021

International Journal of Advanced Trends in Computer Science and Engineering

Available Online at http://www.warse.org/IJATCSE/static/pdf/file/ijatcse191052021.pdf

https://doi.org/10.30534/ijatcse/2021/191052021

\title{
A Framework for Information Technology Auditing in Corporate Digital Operations
}

\author{
Collins C. Ngwakwe ${ }^{1}$, Akinyomi O. John ${ }^{2}$ \\ ${ }^{1}$ University of Limpopo, South Africa, collins.ngwakwe@ul.ac.za \\ ${ }^{2}$ Mountain Top University, Nigeria, akinyomio@gmail.com
}

Received Date : August 07, 2021 Accepted Date : September 16, 2021 Published Date : October 06, 2021

\begin{abstract}
This paper provides a conceptual framework for auditing in digital operations. It aims to create and position digital auditing framework as a pragmatic lens for organisations in the embryonic, growth and established stage of digitalisation. The paper applies a conceptual approach by engaging in a brief conceptual review, thereafter, relying on extant literature and professional documents, the paper creates a maiden framework for digital auditing, which contributes to the literature on information technology auditing. Accordingly, this paper provides a digital auditing framework for professionals, academics, and researchers; in addition, it provides an agenda for further research to develop this initial framework by adding more encompassing nodes of digital auditing technological imperatives.
\end{abstract}

Key words: Digital auditing, IT Auditing, Digital operations, Auditing 4.0

\section{INTRODUCTION}

The $21^{\text {st }}$ century marks a time in human history when the use of computers has become a common occurrence. This is why this period is generally described as the information age, computer age, or digital age [1]. Reliance on information technology (IT) has become a common phenomenon among modern business organizations globally [2]. This is not farfetched as IT is being deployed in almost every facet of human life today. According to Islam (2016), IT has become unavoidable for the normal operations of businesses, regardless of their magnitude and sophistication all over the world. In the field of accounting generally, IT plays crucial roles as it makes it cost-effectively practicable for professionals to gather financial data, record financial transactions, process the data into the different forms of financial reports, and disseminate the resulting information to its many users across departments and geographical frontiers (Taiwo, 2016). Accordingly, the age of digital auditing has come to the fore in response to the technology wheels of change in the industry of which the pivotal factor is the industrial digitisation of operations and services [3].

The overarching objective of this paper is to evaluate developments in information technology auditing to cope with

developments incorporate digital operations in the age of globalization. The paper contributes by creating a conceptual framework for auditing in digital operations. The practical implication for the auditing profession, therefore, hinges on the need to advance information technology skill of auditors, training, and digital asset acquisition to fortify the consulting job of auditors to align with the digital globalisation. The problem warranting this framework initiation is that, whilst business and management practices had for some time began innovation along the precincts of emerging technology, the audit profession and accounting and auditing standard setters appear somewhat late in embracing technology. The group's lateness and/or hesitancy partly lies with their obsolete tools of measurement and communication [4].

\section{CORPORATE DigITAL OPERATIONS AND INFORMATION TeChNOLOGY AUditing}

Conventionally, auditing represents an autonomous assessment of an entity's management claims that usually adhere to some rules developed by a regulatory body. This could either be in form of an external assignment carried out by qualified public accountancy firms or an internal assignment accomplished by the internal audit unit of the entity [5].

Information technology auditing is an emerging auditing function, which assesses whether an information system secures resources, preserves data reliability, accomplishes an entity's objectives adequately, and utilizes resources skilfully. According to [6], some of the fundamental objectives of IT auditing includes an appraisal of the reliability and sufficiency of different functional controls and advancement of such controls at a fair cost. Others includes establishing the 
degree of conformity with the rules, determining the degree to which the firm's IT resources provide security for the firm, establishing the exactness and the integrity of the information processed via the IT, and establishing the efficacy and the capability of different IT hardware and software in the organization [6]. IT audits might be carried out in the course of a corporate process appraisal or as component of a bigger connected audit in which accounting and technology auditors work simultaneously (like during annual report audit) or possibly while internal functioning and IT auditors work together to evaluate corporate processes along with associated systems. [5].

Corporate digital operation and process is the assimilation of digital technology into every aspect of an organization, essentially leading to a modification of the manner business operates and provides values to its internal stakeholders, such as employees and management; and external stakeholders, such as clients, suppliers, consumers, creditors, etc.) (Bruno, 2017). It necessitates establishments to think out of the box, become contented with trying new grounds and taking calculated risks bearing in mind the possibility of failure. It integrates techniques for detecting, identifying, and appropriately responding, whereas conceivably encouraging active learning and optimization. It represents the commencement of a corporate discipline, which culminates in enhanced organizational dexterity. It includes an all-inclusive set of approaches and supporting technologies connected with how organisations provide value through a digital platform in real-time.

The first type of corporate digital operations is 'business process operations'. Business organizations globally have in recent times pay serious attention to their processes [3]. The application of modern technologies such as the data analytics, application programming interface, machine learning, and similar modern tools provide such an organization with precious innovative means of revamping processes all through the organization; having cost optimization, decreasing cycle times as major objectives, without jeopardizing quality [3]. A second type of corporate digital operations is 'business model transformation'. This has to do with revamping a business model which connotes integrating technology since this will enhance income and advance customers' experience, instead of merely applying technology for technology's sake. This model concentrates on the immeasurable and unlimited potentials of businesses [3].

Another type of corporate digital operations is 'domain operations'. Domain operations happen in a situation where a business is effectively capable of extending its scope and coverage into additional areas fruitfully. A popularly recent example which quickly comes to mind is Amazon which added Amazon Prime (its streaming platform), in addition to
Amazon Web Services (AWS), which is currently one of the leading cloud computing service. These two areas were previously controlled by foremost players in their corresponding areas, nevertheless, the huge financial support being enjoyed by Amazon facilitated it to make massive progress when entering these new markets.

Last but not the least among the types of corporate digital operations is 'culture/organizational operations'. Complete, durable digital process and operation entails reformulating institutional mind-sets, processes, talents, and competences for the digital environment. Topmost organizations acknowledge the fact that digital operations need responsive workflows, an inclination to learning, unlearning and testing, segregation of duties and devolved decision taking, and a better dependence on corporate ecosystems. Such corporations' management participates aggressively towards initiating change in their respective organizations.

\section{CONCEPTUal Framework}

The functional constituent of the professional service of auditors can be analogous to legal function, which should provide equitable, fair, and objective protection to all parties bound by economic contract. In both professions, substantial evidence is highly apposite; in addition, the two professions complement and draw synergy from each other. For instance, effective auditing cushions the company and the audit firm from potential legal actions by corporate stakeholders. In the same vein, effective audit evidence functions as judicial evidence, which the legal profession applies to validate arguments in commercial and related disputes. However, the $21^{\text {st }}$ century growth in complex and advanced digital technology has added to the complexity of audit service evidence given that many evidential matters continue to metamorphose from hard to digital genre. On the one hand, for the older generation of auditors and accountants, the speed of digital technology innovation is unnerving, unprecedented, and portends looming professional extinction except with further training. For the younger generation of auditors and accountants who are more technology avid, digital technology ubiquity and evolution offers opportunity.

Some current and past legal actions against auditors arise from insufficient evidential matter upon which auditors rely to reach conclusions regarding true and fair view financial and operating conditions of an entity. Herein lays the significance of digital evidence (digital auditing), which is to provide additional evidence amidst bourgeoning information technology advancement and automation in the $21^{\text {st }}$ century business manufacturing and service processes.

Never in history has the important function of auditing been so intractably webbed in the complex technology of the modern century in addition to innovation and disruptive 
velocity of artificial intelligence (AI) [7]. Hence, more than ever, the auditing profession has had to embrace technology innovation, resilience, and tenacity to provide verification and certification on the effectiveness of business manufacturing, financial, and service operations that pass through digital platforms. Given the colossal nature of modern digital technology and the myriad of bourgeoning business transactions passing through the digital platforms and gateways, this framework is only an initiation for further research agenda on capturing the multifaceted dynamics of electronic auditing perspective into a researchable framework. Hence, this paper's framework in Figure 1 remains flexible for further addition, realignments of nodes and expansions.

Accordingly, innovations that span through advancements from first to fourth industrial revolution has reached an unprecedented technological efficiency and effectiveness [7], [8]. This advancements dovetail with modern information communication and has become disruptive to conventional accounting and auditing. Chief amongst the innovation spurring changes in auditing are:

"XBRL-based structured digital financial reports; Knowledge-based systems and other application of artificial intelligence; Blockchain-based distributed ledgers" [7 p.13]

\subsection{A Conceptual Framework for Auditing in Digital Operations}

Accordingly, the paper develops a 'Conceptual Framework for Auditing in Digital Operations' (see Figure 1) with description of the abbreviations in Table 1. Given the bourgeoning nature of digital technology and its impact on commercial operations and auditing, the framework presents a framework that categorises digital auditing into current and future state of digital auditing. This framework does not claim that the suggested description of current and future state of digital auditing is sacrosanct, rather is attempts to capture key technological and operations issues that auditors navigate through for evidence gathering and attendant auditing. Accordingly, the authors initiate an apparently initial conceptual framework auditing in the era of digital operations. As shown in Figure 1, the authors construct the framework into two broad eras, namely the current state of auditing in digital operations and the future state of auditing in digital operations.

The current state of digital auditing leans on five key digital information descriptors. These are the blockchain-based distributed ledgers (BCBDL), The XBRL-based structured digital financial reports (XBRL-DFR), Artificial Intelligence and knowledge-based systems (AI\&KBS), Mutual distributed ledgers (MDLs) and The Bitcoin (BITC) [7], [9]. Furthermore, the authors present another phase - the future state of digital auditing under the configuration of Auditing 4.0 (A-4.0). although some elements of future state of digital auditing has kicked in, the paper still regards the entire spectrum of Auditing 4.0 as a phase is beginning to develop and going into the future with expanding capabilities and mutations that will keep unfolding with the passage of time and blossoming information chips. Two tentacles pivot the success of the future state of digital auditing, namely the A-4.0 Technology and the A-4.0 Principles [4]. The A-4.0 Technology inclines solidly on five key components of digital technology platforms whilst awaiting further additions. These are Cyber Physical System (CPS), Internet of Things (IoT), Internet of Services (IoS), Radio Frequency Identification (RFID), Global Positioning System (GPS). Allied to the above A-4.0 technology are the A-4.0 principles that lubricate the technology platforms to offer seamless functions. These principles include Interoperability (INToP), Virtualization (VTLZ), Decentralization (DTLZ), Real-Time Capability (RTC), Modularity (MDL), the technology aspects and principles are well-described [4].

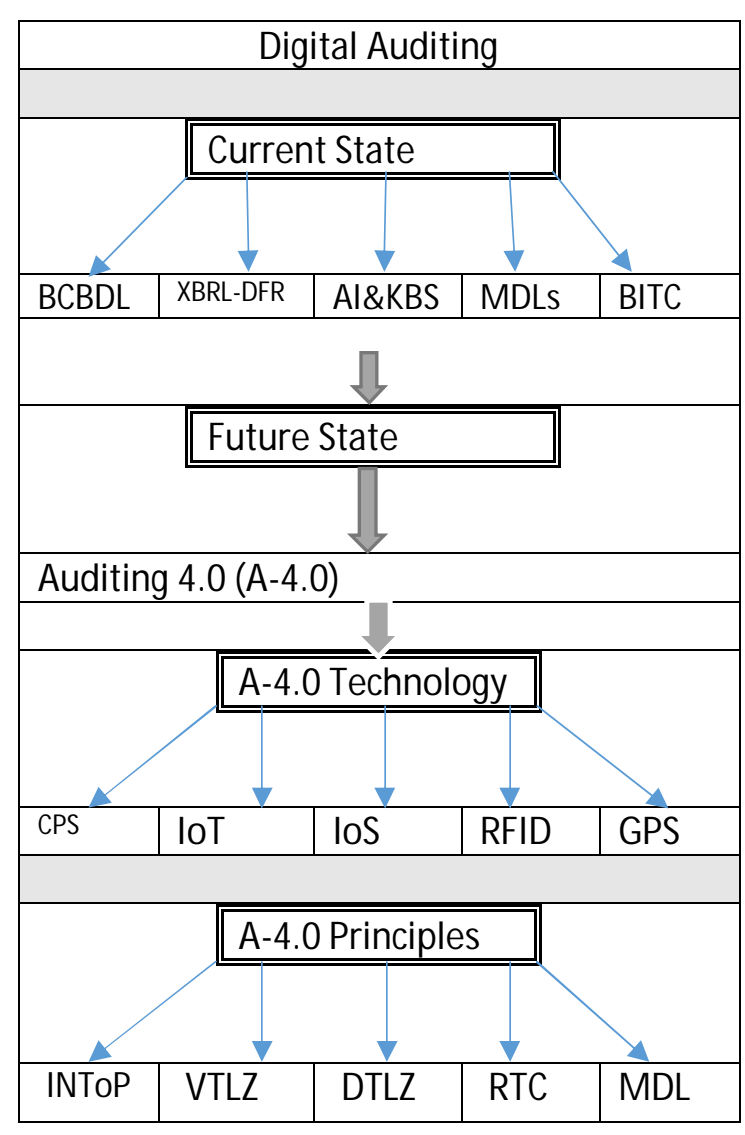

Figure 1: A Conceptual Framework for Auditing in Digital Operations Source: Authors 
Table 1 Key to Figure 1 Abbreviations

\begin{tabular}{|l|l|}
\hline \multicolumn{1}{|c|}{ Abbreviation } & Full Name \\
\hline BCBDL & $\begin{array}{l}\text { The blockchain-based distributed } \\
\text { ledgers }\end{array}$ \\
\hline XBRL-DFR & $\begin{array}{l}\text { The XBRL-based structured digital } \\
\text { financial reports }\end{array}$ \\
\hline AI\&KBS & $\begin{array}{l}\text { Artificial Intelligence (AI) and } \\
\text { knowledge-based systems (KBS) }\end{array}$ \\
\hline MDLS & Mutual distributed ledgers \\
\hline BITC & Bitcoin \\
\hline & Future State Abbreviations \\
\hline CPS & Cyber Physical System \\
\hline IOT & Internet of Things. \\
\hline IOS & Internet of Services \\
\hline RFID & Radio Frequency Identification \\
\hline GPS & Global Positioning System \\
\hline INToP & Interoperability \\
\hline VTL & Virtualization \\
\hline DTLZ & Decentralization \\
\hline RTC & Real-Time Capability \\
\hline MDL & Modularity \\
\hline
\end{tabular}

\section{CONCLUSION}

The era of digital auditing has come to the fore in response to the technology wheels of change in the industry of which the pivotal factor is the industrial digitisation of operations and services [3]. Accordingly, the transformation of business along the ever-increasing frontiers of digitalisation of previously man-powered and/or mechanical operations and services requires additional security of digital genre, hence digital evidence to support decision making is apposite both in auditing and financial operations of businesses. This therefore requires that proactive chief financial officers in diverse organisations and auditors (public or private) should be metamorphosing from their previously hardbound evidence and/or fact supporting documents to digitalised big and mega-data operators to bestow quality and credibility in financial and auditing functions that meet the digital age. Given the nascent nature of digital transformation, the concepts of digital technology, information and hence digital evidence with the attendant implication for accounting and auditing functions is also nascent and even somewhat unversed to many professionals and organisations. This paper has therefore provided both a professional and academic framework for digital auditing as a lens for organisations in the embryonic stage of digitalisation. In addition, this paper provides a digital auditing teaching and learning framework for academics and researchers and provides an agenda for further development of this initial framework by adding more encompassing nodes of digital auditing technological imperatives. For instance whilst this paper's focus is on current and future lens of digital auditing, further framework should look at beyond the future digital auditing and may consider emerging technology such detecting objects via voice sensor [10] .

\section{REFERENCES}

1. D. J. Borkovich, and P. D. Noah. Big data in the information age: Exploring the intellectual foundation of communication theory. Information Systems Education Journal, vol. 12. No.1, pp. 15-26, 2014

2. D. Shrestha, T. Wenan, B. Gaudel, S. Maharjan, and S. R. Jeong. An exploratory study on the role of ICT tools and technologies in tourism industry of Nepal. International Conference on Mobile Computing and Sustainable Informatics, pp.93-110, 2021

3. PWC. Audit 4.0 https://www.pwc.ch/en/insights/disclose/27/audit-40-pa rt-2-high-performing-auditors.html, 2021

4. J. Dai and M. A. Vasarhelyi.. Imagineering Audit 4.0. Journal of Emerging Technologies in Accounting, vol. 13, no.1, pp. 1-15, 2016

5. J. W. Merhout and D. J. Havelka. Information technology auditing: A value-added IT governance partnership between IT management and audit, Communication of the Association for Information System, vol.23, no.26, pp.463-482, 2008

6. J. Pathak. Information technology auditing: An evolving agenda. New York, Springer, 2005

7. C. Hoffman. Accounting and auditing in the digital age. URL: http://xbrlsite. azurewebsites. net/2017/Library/AccountingAndAuditingInTheDigital Age. pdf , 2017

8. K. Schwab. The fourth industrial revolution. Crown Books: New York, 2017

9. V. Brühl. Bitcoins, blockchain und distributed ledgers. Wirtschaftsdienst, vol.97, no.2, pp. 135-142, 2017

10. M. S. Mohammad, B. Pranitha, S. G. Pandula, and P.t Sree, Object detection with voice sensor and cartooninzin the image. International Journal of Advanced Trends in Computer Science and Engineering vol. 10, no. 4, pp. 2762 - 2767, Sept 2021 